\title{
Teodor Negru
}

Radboud Universiteit, Faculteit der Filosofie, Theologie en Religiewetenschappen, Erasmusplein 1, NL-6525 HT Nijmegen

theonegru@yahoo.com

\section{Self, Agency and Autonomy in Dynamical Living Systems}

\begin{abstract}
In this paper, I intend to offer a new explanation of the self both from the biological and dynamical systems theory perspectives. This means that I support the idea that the self is a consequence of biological control mechanisms, either of the internal processes or resulting from the interaction of an organism with the environment. From the perspective of the dynamical systems theory, the self will be approached as a bundle of patterns resulting from adapting of a living system to the conditions of the environment. In the first part of the paper, the self is understood starting from three characteristics of the living systems, resulting from the self-organisation of the organic matter: identity, unity and self-maintenance. In the second part, I discuss one of the most important characteristics of the self: agency. The sense of agency is approached as being made of three components: coupling of the organism with the world, the control of the internal and external processes, and prediction. In conclusion, I discuss the issue of the relation between the self and autonomy, considering the self as a consequence of the degrees of freedom of a living system.
\end{abstract}

\section{Keywords}

self, agency, autonomy, dynamical systems, autopoiesis

\section{Introduction}

In the history of philosophy, the idea of self has been one of the most challenging issues, which in recent years has been approached from the perspective of current findings in neuroscience, behavioural science or psychiatry. Thus, new topics for debates have been put forward, which allowed a discussion about the neurological correlate of the self, or its interactive, behavioural dimension, or even the pathology of the self. Moreover, the proliferation of the approaches resulted in theorising and discussing several types of self. This was noticed by Strawson, who listed several of these recently theorised forms of self:

"... the cognitive self, the conceptual self, the contextualised self, the core self, the dialogic self, the ecological self, the embodied self, the emergent self, the empirical self, the existential self, the extended self, the fictional self, the full-grown self, the interpersonal self, the material self, the narrative self, the philosophical self, the physical self, the private self, the representational self, the rock bottom essential self, the semiotic self, the social self, the transparent self, and the verbal self." (Strawson 1999, p. 100)

Thus, in current literature, the self is understood as a multi-dimensional phenomenon, which should be discussed from a philosophical perspective and by the joint contribution of several approaches that belong to various fields of study.

The discovery of this multi-dimensional character of the self has determined the change of the classical metaphysical conception of self, as theorised by Descartes (1996 [1641]). According to the Cartesian conception, the self is an 
entity of spiritual nature, purely rational; it is the guarantor of the epistemic certainty and the cognitive core of man's mental life. ${ }^{1}$ Against this conception, current researches have highlighted the importance of corporality for constituting the self (Gallagher 2005; Zahavi 2005), showing that the self is a discontinuous phenomenon (Strawson 1999), of phenomenal nature (Zahavi 2003; Zahavi 2005), which can be understood as having a fictional character, as the centre of narrative life of a person (Dennett 1992) ${ }^{2}$ or having an interpersonal character (Neisser 1998; Rochat 1995) and which can have several forms, depending on the degree of the biological complexity of organism (Damasio 2010). By these approaches, the conception of the self, as an exclusive characteristic of the human being, was contested, the self became a feature of any living being. Moreover, explaining the self became a necessity from the perspective of the biological mechanisms, which are at the origin of its emergence and function.

Approaching the self, understood to be a part of any biological creature, opens the possibility of understanding it from the perspective of the dynamical system theory. This new perspective results from the fact that living organisms are considered to be dynamical systems, those systems that have a dynamic relationship with the environment they live in. This means that understanding living systems should also include explaining how their state space ${ }^{3}$ emerges and the patterns of action based on which they act in the world.

Thus, starting from the recent approaches of the self, in this paper, I intend to offer a new explanation of the self both from the biological and dynamical systems theory perspectives. This new approach of the self uses several already existing theories, which would be useful to recapitulate in order to understand my way of approaching the self. Firstly, the idea of the self I propose is closer to David Hume's conception (2009 [1739]), which contests the existence of the self as an indivisible entity that would guide our entire mental life. To Hume, the self should be approached as a bundle of impressions and ideas that are interlinking by resemblance or causality relations. Similarly, but from a different perspective, Varela speaks of a selfless self, "a coherent global pattern that emerges through simple local components, appearing to have a central location where none is to be found, and yet essential as a level of interaction for the behaviour of the whole unity" (Varela 1992, p. 11).

The idea that we should not understand the self as a substantial reality, rather that it is a bundle of patterns resulting from the interaction of the adapting mechanisms with which a living being is endowed, is supported in this article, but from the perspective of the dynamical system theory.

The idea of approaching the self in terms of a theory of patterns has recently been discussed by Gallagher (2013). According to him, the self should be seen as a pattern resulting from the dynamic interaction of certain features, such as: minimal embodied aspects, minimal experiential aspects, affective aspects, intersubjective aspects, psychological/cognitive aspects, narrative aspects, extended aspects, situated aspects (Gallagher 2013, pp. 3-4). Unlike Gallagher's theory, I support the idea that, from the standpoint of the dynamical system theory, the self is the result of various patterns of the organism, which aim to maintain its internal organisation due to different perturbations emerging in the internal or external environment. In this approach, the self is not a certain type of pattern, but it is the convergent point of all such patterns that contribute to the organism's adaptation. As a convergent point, the self is not a substantial entity but a consequence of the internal coherence of any 
biological system, which results from the need to coordinate the various adaptative patterns of the organism.

Another idea that has generated recent debates in the current literature is that the self is a consequence of the interaction of some mechanisms at various levels in the organism (Thagard 2014). According to this conception, the self is a multi-level system that results from the integration in a whole of the mechanisms operating at a social, individual, neural, and molecular level (Thagard 2014, p. 145). A similar idea is supported in this article; however, from my perspective, the self results from the interaction of various biological control mechanisms of the human being. This means that any living being, depending on the degree of complexity, has developed in evolution, control mechanisms that adjust the organism's internal states according to external changes. Examples of such control mechanisms are the cell membrane which enables, among other things, the chemiosmotic control, namely, it controls the chemical exchanges between the organism and the environment, or the nervous system, which is responsible for the sensorimotor control of the living system, thus integrating the organism in the environment using perception-action loop, or consciousness, which provides higher-order cognitive control to the living systems. The sense of the self emerges from the integration of all such control mechanisms in a coherent pattern of action, which provides identity and unity to the living organism. ${ }^{4}$

Consequently, the theory of the self I present in this article combines the biological perspective with the dynamical systems theory. From the biological perspective, I try to explain the emergence of the self beginning from its organic origins. This means that I support the idea that the self is a consequence of biological control mechanisms, either of the internal processes or resulting from the interaction of an organism with the environment. From the perspective of the dynamical systems theory, the self will be approached as a bundle of patterns resulting from the living system's adaptation to the environment's conditions. These patterns result from the convergence of internal dynamics of the organism with the external one, whose consequence is the adjustment of the organism behaviour to the changes in the external environment. Considering that the two perspectives are interconnected, I intend to offer a comprehensive approach to understanding the self as a multi-dimensional phenomenon.

1

Even if modern philosophers agreed with the mental nature of the self, they contested the idea that it has a substantial reality. Locke (1979 [1690]), for example, considers the self as a consequence of consciousness, which always accompanies thinking. To Kant (1965 [1781]), the self is approached as a condition of possibility of the unity of experience, meaning as a thought that accompanies any act of knowing.

2

However, these views are not compatible. According to Zahavi (2007), the self is not the fictional center of narrative gravity, but we can speak about various dimensions or levels of selfhood that can be approached differently from the narrative perspective. Thus, from the phenomenological perspective, what we call (minimal or core) self is the first personal giveness of the experiential phenomena, namely what gives the subjective character of experience (Zahavi 2007, p. 184). 3

According to the dynamical system theory, state space represents the totality of the states that a system can occupy during its evolution. 4

This means that, without a self, organisms could not coordinate and join in a coherent whole the adaptative patterns of the control mechanisms of the biological systems. 
To this purpose, in the first part of the paper, I approach the issue of the self from the perspective of self-organisation as a process supporting the emergence and maintenance of the living world. The self will be understood starting from three characteristics of the living systems, resulting from the self-organisation of the organic matter: identity, unity and self-maintenance. In the second part, I discuss one of the most important characteristics of the self: agency. This means that the organisms endowed with the self are not passive parts of the world, but they are systems that can act on it and transform it according to their own goals. It results from the capacity to be an agent that living systems, by means of their biological mechanisms, create a dynamical system with the world while conditioning reciprocally. Therefore, the sense of agency is approached as being made of three components: coupling of the organism with the world, the control of the internal and external processes, and prediction. Starting from here, in the third part, I discuss three types of agency that characterise living systems: minimal, sensorimotor and cognitive agency. These three types of agency are approached both from the perspective of biological mechanisms wherefrom their functionality originates and the dynamical systems theory. In conclusion, I discuss the relation between the self and autonomy, considering the self as a consequence of the degrees of freedom of a living system.

\section{Constitution of the Self in Living Systems}

Self-organisation is the capacity of living matter to configure, in time, biological systems, to self-sustain and self-replicate under the circumstances of environmental pressures. This means that self-organisation is the process of creating certain systems with various degrees of autonomy, depending on their biological complexity. The creation of some autonomous biological systems is not possible without the emergence of the self that is to guide the organism in its process of adapting to the environment. Consequently, self-organisation generates autonomous organisms endowed with a self, which is a consequence of the adaptative patterns of the system. In this way, the self contributes to the autonomy of the living system by coordinating the adaptative patterns in increasingly complex action patterns.

Recent researches of the relation between self-organisation and the self, debating whether the self is merely the result of self-organisation of living matter or it is an important part of this process. An answer to this issue is given by Maturana and Varela (1980), who, from the perspective of the autopoiesis process, ${ }^{5}$ consider that there should be a self that guides the self-production of the components of the living system. Following this interpretation, the self would be a part of the process of self-maintaining the organism. To this, Collier adds (2004) that self-organisation implies the existence of some proto-selves, which should lead to the organisation and emergence of individual selves (Collier 2004, p. 164). This means that the self, as a result of the organism's internal conditions, is a component of the self-organisation process.

From the self-organisation point of view, the self cannot be a prior component of this process because this would mean that the self is a self-contained entity that would add to the self-organisation process. In addition, self-organisation is not guided by an external entity, but it is a control-free process. This means that self-organisation follows laws, resulting from adaptation to environmental conditions; hence, there is no need to control it from external forces. 
To conclude, the self is a consequence of self-organisation but contributes to maintaining the self-organisation process and the organism's viability. In other words, the self results from the aggregation of the components in a unitary whole, which is to resist the environmental disturbances. Moreover, it contributes to the process of adaptation, acting as an organising principle that helps to configure a system adapted to the environment. This is possible because one of the functions of the self is to self-produce the internal processes that help to the very constitution and preservation of the biological organism to which it belongs. Thus, one can say that the self guides the self-production of the components of the living system, maintaining the system identity and unity. In this way, self-organisation produces a system characterised by identity, unity, and self-maintenance. These features are minimal requirements for the emergence of the self in the living system. It results from here that it is important to show how these three basic features of a self-organised system contribute to the emergence of the self of a living system.

\section{a) Identity}

Identity is a characteristic of a living system resulting from maintaining its internal organisation constant (Maturana \& Varela 1980) and its internal parameters despite the perturbations of the environment. In this interpretation, one does not talk of a self-identity or a personal identity. We can discuss this type of identity only in the case of organisms with higher-order cognitive skills. In the minimal sense, the identity can be understood in terms of the autopoietic theory, as being a result of the operational closure ${ }^{6}$ of a living system, whereby processes, which support the functioning of the organism, also create the conditions for their emergence and development (Di Paolo \& Iizuka 2008, p. 411). It is the case of autocatalytic cycles that can sustain and regenerate by themselves from these processes emerging their identity (Di Paolo \& Iizuka 2008 , p. 411). The constitution of identity means the emergence of a global coherence of internal interlinking processes whose goal is their own production (Varela 1997, p. 73). Identity, in this sense, is an operational identity, a consequence of the production by the system of some recursive adapting patterns (Negru 2016a).

Thus, identity is approached from the perspective of an organism's homeostatic character, which tends to maintain, via the patterns of action that they create, the internal equilibrium, despite the perturbations of the environment. An important role in this process is played by what the organisational view calls second-order constraints, whose role is to regulate the organism (Moreno \& Mossio 2015). According to this theory, second-order constraints intervene when the stability of the system is endangered, introducing an order

According to Maturana and Varela (1980, p. 78), living organisms are autopoietic machines, which means that they are characterized by the fact that the network of internal processes contributes to maintaining and regenerating the internal components and processes without having an external aim.

Operational closure (Maturana \& Varela $1980)$ is a consequence of the recursivity of the internal processes of the biological organism, which determines unitary system. Operational closure does not mean that the system is closed, that it does not communicate with the exterior. On the contrary, it has numerous interactions with the environment but its responses to the external disturbances are given in a unitary manner, as a whole. 
pattern that would restore the order in the organism. In other words, second-order constraints act top-down on the organisational closure, maintaining it and thus, enabling the adaptation of the organism to the perturbations of the environment. Identity results from the dynamics between the first-order constraints, which are consequences of the cohesion among parts and which contributes to the maintenance of the stability of organisational closure, and the second-order constraints, which stabilise the organism whenever internal order is endangered. But, even in this approach, we still talk about an operational identity that results from the functional constraints of the system which determines recursive action patterns at its level.

Approaching the homeostatic character of organisms from the organisational view can be completed with the perspective of dynamical systems. From this point of view, any living system's goal is to lower internal entropy by minimising their free energy and maintenance of the organism in a limited number of states (Friston 2010). This means that the living systems, as dynamical systems, tend to maintain constant their internal states by creating some order patterns. These patterns tend towards the organism's behaviour (i.e. attractors); they are not randomly created but configured according to the organism's adapting needs. In other words, attractors are patterns that reunite several system variables, thus providing a response of the entire organism to the variations of environment. A living system is characterised by several such patterns of action, which have as their goal the survival of the organism despite the perturbations of the environment.

In Juarrero's terms, this means that "as a dynamic system, [...] an autopoietic system's identity is given by the coordinated organisation of the processes that make it up, not the primary material of its components" (Juarrero 1999, p. 125). From this perspective, identity means that all such patterns of action converge towards the same result: constantly maintaining the organism and its internal organisation. Thus, at the level of the system, a bundle of patterns configured in a shared state space emerges. This bundle of patterns that coordinates itself spontaneously, with a diffuse centre, determines the emergence of an incipient self.

To conclude, identity in its minimal form results from recursivity and coordination of the system's basic processes. This operational identity implies an incipient self, resulting from the tendency of the living system to maintain its internal parameters.

\section{b) Unity}

The unity of a living system is its capacity to form, based on its self-referential processes, ${ }^{7}$ an internal space whereby the organism sets its own limits from the surrounding world. In the autopoietic tradition, this means that unity is the result of what also makes the identity of a living organism - operational closure (Varela 1997). ${ }^{8}$ Unity and identity are thus a consequence of the coherence of the network of processes that make the system: "the autopoietic mechanism will maintain itself as a distinct unity as long as its basic concatenation of processes is kept intact in face of perturbations" (Varela 1997, p. 76). From this perspective, the recursive character of the internal processes is at the origin of the emergence of a system that is distinct from the surrounding world, which reacts as a whole to the changes outside it. 
From the point of view of the constitutive processes, unity is also a result of the organism's internal constraints. According to the organisational view (Moreno \& Mossio 2015), owing to organisational closure, biological organisms can self-constraint, namely, to modulate the ongoing thermodynamic flow they are exposed to. Thus, internal constraints create a mutual dependence between the components of the system determining its action as a whole considering external perturbations.

Unity is also a consequence of the homeostatic tendency of the system to maintain its internal parameters constant. Any living system is characterised by resistance to variance (Rudrauf \& Damasio 2006, p. 438), which refers to the capacity of any organism to maintain its internal equilibrium to deal with the ongoing perturbations. This process involves a response of the organism as a whole, which involves the preservation of its operational unity and identity.

Another way operational closure contributes to constituting the unity of the system is by building a boundary of the system. The boundary of the system is seen as a result of the internal components of the organism, whose role is to maintain the coherence of its internal processes as well as to provide communication channels between the interior and the exterior of the organism (Ruiz-Mirazo \& Moreno 2004, p. 244). Thus, boundary represents the physical delimitation of the organism, which provides the maintenance of its internal processes, but also the interaction with the environment, creating an open system, which could receive and respond to the changes in the environment. Thus, the boundary is not a barrier that contains the organism, but it is a control structure that models the organism's internal space in a unitary whole, taking into account the changes of the world where it lives.

From the perspective of the dynamical systems, the role of the boundary is to constitute a state space of the systems. Facilitating the energetic and chemical exchanges with the exterior constitutes the states of the organism that may be occupied in relation to the environment. In this state space, the organism's action patterns, whose complexity is given by its biological developmental level, will be constituted. The unity of the system also results from the coherence of these processes in the system's state space, which together contribute to the survival of the organism as a whole in the environment it lives. The unity of the organism can be considered as an operational unity, which results from the dynamics of its patterns of action, whose goal is to maintain the internal stability, considering the responses that the organism, as a whole, has to provide to the changes in the environment.

\section{c) Self-Maintenance}

Self-maintenance is the capacity of an organism to maintain its identity and unity despite the perturbations of the environment, without any exterior sup-

Self-referential processes are those processes that contribute, according to the autopoietic approach, only to producing and maintaining the network of constitutive processes, without aiming at creating something external.

8

In this approach, unity means that the organism is a distinct entity in the environment where it lives, responding as a whole to the challenges from the environment. And, identity represents the characteristic of the organism to maintain its internal organisation constant and to occupy the same states in its state space. 
port. This capacity, constitutive to any living system, was called robustness (Barandiaran \& Moreno 2008) or, it can also be met in the current literature as self-determination (Mossio \& Bich 2014) or in the organisational view, it is called self-maintenance (Mossio \& Moreno 2010; Moreno \& Mossio 2015). A common characteristic of self-maintenance, in these approaches, is the fact that the system can act on its boundary conditions (Barandiaran \& Moreno 2008, p. 332) or the existing conditions (Mossio \& Bich 2014, p. 1090). In other words, self-maintenance involves self-referentiality of the internal processes of the organism, which is at the origin of its identity and unity. The living system acts on the internal components and on the energy flows to which it is exposed from the exterior by constraint, which means that it has a self-constraining capacity (Mossio \& Bich 2014; Moreno \& Mossio 2015). This results from the necessity of the organism to regulate the flows and the internal processes to maintain the continuity of the existence of the organism despite the perturbations of the environment. Self-constraint involves the existence, at the organism level, of a circular causality between the parts and the whole, whereby the parts constitute the whole, which, in turn, by the new emerging properties, determines the parts to behave in a certain way. In other terms, "the organisation produces effects [...] which, in turn, contribute to maintain the organisation" (Mossio \& Bich 2014, p. 1090). It results from here that the organisation of a living system is the consequence of the dynamics of the parts' cohesion and the internal processes, which create a whole that acts by constraints even on the parts that create it. In terms of the organisation view, this means that at the level of the system, a new causal regime emerges, which determines a closure of constraints that regulate the entire functionality of the organism (Mossio \& Bich 2014; Moreno \& Mossio 2015).

In conclusion, self-maintenance is a consequence of operational closure, which involves the realisation of a relation of dependence between the parts of the organism by the constraints that such organism, as a whole, exerted on its components. From the point of view of the dynamical systems, this means that at the level of the system, its constitutive processes determine a circular relation between parts and whole, whereby the system regulates its internal processes and the exchanges with the external environment. In Juarrero's terms (1999), this means that the organisation of the system is the result of the dynamics between the bottom-up constraints, the result of the aggregation of the system's components and the top-down constraints, which determine the possibility of new states to emerge, in the state space of the system as a whole. ${ }^{9}$ Thus, the system can access some new responses to the challenges in the environment, which the system's independent parts do not have. In this context, self-maintenance represents a living system's characteristic to self-maintain despite the challenges in the environment, by constituting a state space, where responses emerge, which its parts may not be able to provide. In this way, a sense of self is created as a result of the emergence of some new response possibilities of the organism as a whole.

Identity, unity, and self-maintenance are the three characteristics constitutive of living system, which is also at the origin of the emergence of an incipient self of the organism. Thus, the self is the result of the internal processes recursivity, whereby the living system creates its own components and acts on its boundary conditions. Moreover, the self is a consequence of the organism's unitary character, which, as a whole, responds to environmental changes. In the process of constituting the self, the self-constraint capacity of the living 
organisms - whereby it regulates the energetic flows it has with the exterior - also contributes. In this context, an important role is played by what the autopoietic tradition called organisational closure. Owing to the self-generating character of the basic processes, the organism gains identity, unity, and self-maintenance. These are also the basic characteristics that determine the emergence of a self and, at the same time, they determine the living system autonomy. Last but not least, to the emergence of the self, a significant contribution has circular causality characterising any living system, given by the bottom-up and top-down processes dynamics, wherefrom it results in the organism's need to survive as a whole.

It results from here that the incipient self is not a self in the classical meaning, but it is a bundle of patterns that result from the organism's homeostatic character, whereby the system gains stability and equilibrium. This organic self is a cellular self (Deacon 2011) or biological self (Thomson 2007, p. 260), which is based on the processes whereby the organism aims at surviving under the pressures of the environment. The basic self is a feature of any living system that needs to adapt to the conditions of the environment where it lives, by regulating and controlling its internal variables.

\section{Self and Agency}

One of the important characteristics of living beings is that they are not passive parts of the world we live in, but they have a propensity to action. This means that any organism is an agent that responds to the changes in the environment and act on the environment to modify it according to its own goals. Primitive forms of agency can also be met in unicellular organisms that involve only the basic motility of the living system (Deacon 2011). Moreover, highly-organised organisms exhibit advanced forms of agency, which do not consist in the mere moving away from potential threats or toward food sources. In advanced forms, agency involves the discovery of new action possibilities in the external world and even the development of long-term plans so that the organism may achieve its goals.

In the current literature on biological autonomy, there have been several attempts to explain the characteristics of agency, in any form whatsoever. Thus, an approach to agency considers that it is characterised by individuality, interactional asymmetry, and normativity (Barandiaran, Di Paolo \& Rohde 2009). According to this approach, individuality refers to the fact that organism represents a system different from the environment; interactional asymmetry consists of the fact that the organism is coupled with the world, being conditioned by it, whereas normativity refers to the fact that agents, in achieving their goal, behave according to some norms.

Another way to approach minimal agency belongs to the organisational view, which approaches agency from the perspective of four features: the ongoing interaction with the environment, the exertion of constrains irrespective of the amount of energy invested by the agent, organism's behaviour according to certain norm or goal, and the exertion of constraints on its boundary con-

9

An example of such dynamics is the case of Benard cells (Juarrero 1999, p. 141). After self-organizing by heating below, in hexagonal, rolling cells, water molecules become dependent on one another. Thus the behaviour of each molecule is guided by the behaviour of the emerging whole. 
ditions (Moreno \& Mossio 2015, pp. 92-93). In addition, biological systems are considered adaptive agents, which, because they are homeostatic systems, can regulate their behaviour to be able to face the perturbations in the environment (Moreno \& Mossio 2015, p. 99). Such an approach is conducted from the perspective of the organisation of a living system, which means that autonomous agents are understood as having the capacity to regulate the boundary conditions as a consequence of their internal dynamics.

Notwithstanding, an approach of the agency of biological organism should also take into account the dynamics which the organism has with the internal and external environment of the living system. To the extent that the organism forms a dynamical system with the environment, by conditioning reciprocally, agency should be regarded as the result of the dynamics between organism and environment, whereby the adaptivity of the organism to the environment is enabled. From this perspective, we consider that agency is the result of three basic characteristics of a living system: coupling the organism with the world, the control of the internal processes dynamics and the interaction with the environment, and the organism's predictive capacity.

\section{a) Coupling with the World}

Even if they define their own living space in the environment, living systems are not completely separated from the environment they live in. On the contrary, getting information on the changes in the environment and the energy exchange with the environment are important processes for the survival of the living system. This implies the fact that the living system and the world are coupled in a constitutive manner, namely, that the two exist in a recurrent interaction characterised by reciprocal perturbations (Maturana \& Varela 1992, p. 75). From the autopoietic perspective, repetitive interactions between the living system and the environment determine their mutual conditioning.

In terms of organisational view, this relation of mutual determination between the organism and the world is not symmetrical, to the extent that the organism is the one that guides this interaction, according to the norms it imposes and taking its goals into account (Moreno \& Mossio 2015, p. 91). In other words, living organisms have intentional skills, whereby they are originally oriented to detect external signals and to find the best ways to survive in the world. In this case, a self is needed whereby the dynamics of the organism' internal needs are coupled with the dynamics of the external environment. Thus, the system's adaptative patterns are coordinated with a view to realising the connection between the interior and the exterior.

This means that any living system, by means of its actions, which represent a response to external perturbations, is a causal source, namely, a self that maintains an ongoing connection with the world (Moreno \& Mossio 2015, p. 91; Ruiz-Mirazo \& Moreno 2012, p. 35). This self is not merely a situated self-reflecting the needs of the organism at a given moment, but it is an interactive self also reflecting the connections between the organism and the world.

In this way, the living system is defined as an agent whose autonomy consists both in an internal constitutive dimension, implying the preservation of organisational closure, and in an external interactive dimension, implying the maintenance of its internal organisation considering the perturbations in the environment (Bich \& Moreno 2016, p. 13; Moreno \& Mossio 2015; Ruiz-Mirazo \& Moreno 2012, p. 35). In this case, we talk about autonomy as 
a result of the possibilities of the organism to act in the world, whose goals are to maintain its identity, given the constitutive coupling with the environment. It results from here that the organism's interactive processes act as constraints, which determine the organism's self-maintenance, given the changes in the external environment (Barandiaran \& Moreno 2008, p. 332; Moreno \& Mossio 2015). Coupling with the world also causes the emergence of some new types of constraints in the organism besides the constitutive ones, as a result of the internal organisation of organism. The constraints resulting from the interactive processes model the inner space of the organism, according to the environmental conditions, which results in the emergence of some new responses of the organism as a whole to external changes.

These responses, which imply the regulation of structural coupling, represent the adaptive processes, which give rise to adaptive agency (Barandiaran \& Moreno 2008; Froese \& Di Paolo 2011). From this perspective, agents are considered as being able not only of compensatory responses but also of complex behaviour (Barandiaran \& Moreno 2008, p. 332). In other words, constitutive coupling with the world affords organisms, depending on their biological complexity, to respond to changes and detect possibilities to act in the world. In other terms, autonomous cognitive systems act as agents, maintaining and regulating the ongoing sensorimotor loops, whereby they maintain the connection with the world (Di Paolo \& Iizuka 2008, p. 411). It results from here that the connection between the organism and the world can be approached at several levels that depend on the capacities of the organism to adjust to and act in the environment.

From the point of view of the dynamical systems, the structural coupling of organism with the world means that the living system forms a dynamical system with the world. In terms of this theory, living organisms are considered autonomous agents, aiming through their actions to satisfy some internal or external goals, being under continuous long-term interaction with the environment (Beer 1995, p. 173). From this perspective, living organisms and their environment are regarded as two separate dynamical systems that have convergent dynamics, meaning that the trajectories of the two systems influence reciprocally, determining the emergence of new behaviours in the case of agents, which otherwise would not have existed (Beer 1995, pp. 182-183). Thus, the idea of the organism's constitutive coupling with the world appears, in terms of the dynamical system theory, as the issue of the dynamical convergence of the two systems involved.

This is possible due to the relation of circularity existing between the living system and the world, whereby certain parameters of one of the systems can turn into the other's state variable (Beer 1995, p. 181). The relation of circularity ${ }^{10}$ refers to the fact that organisms acting on the world receive a response from the exterior, which becomes a variable for the new action. In this way, living systems adjust their internal dynamics, resulting from the self-organisation of the components, with their external dynamics resulting from the perturbations in the environment. Moreover, the consequence of this relation of circularity is that at the level of the system, a state space emerges, made up of endogenous and exogenous variables of the system, where patterns of action with many degrees of freedom are configured. 
This state space contains those possibilities of response that enable the organism's adaptation to the environment, determining the configuration of certain organisms' trajectories (Beer 1995, p. 184). In this state space, the organism's behaviour as a whole is determined, selecting those patterns of action that facilitate the organism's adaptation to the environment. For this, there is no need for a control centre that should guide the emergence of such patterns. Thus, agency results from spontaneous, self-organising coordination of processes that span organism and environment (Kelso \& Engstrøm 2008, p. 105). Even if, from this perspective, one can speak of a self in the classical meaning, it emerges as a result of the convergence of these patterns of action whose goal is the organism's survival.

To conclude, a constitutive coupling of the organism with the world implies that organism, by its adaptive mechanisms, acts on the world, ensuring its survival. This means that the self is connected constitutively with the world as it is oriented towards detecting the possibilities of action in the environment. From this perspective, one can say that living systems possess an interactive self, the result of the multi-level relations which the organism has with the world, which is not also a centred self, being merely the diffuse point of convergence of the organism patterns of action.

\section{b) Control of Internal Processes and Exchanges with the Exterior}

Even if the agency of living systems does not imply a control centre for all the actions of organisms, there should still be a way to coordinate them. Coordination, as an important characteristic of the self, implies the order and coherence of the systems' adaptive patterns so that the organism as a whole resists disturbances from the environment.

In terms of organisational view, this is explained by the constraints generated by the organism's internal organisation. Organisational closure, which is at the basis of the identity and unity of any living organism, is understood as mutual dependence between constraints (Moreno \& Mossio 2015, p. 20). In other words, the network of recursive processes which are at the origin of the emergence of biological organisms and their autonomy creates a network of constitutive constraints that mutually condition. As we have seen, it results from here that living organisms have the capacity of self-constraint, which means that they generate the constraints, which represent the requirements for maintaining their internal organisation (Mossio \& Bich 2014, p. 1114).

It can be said that at the origin of agency, there is the capacity of living organisms to act on their own internal organisation by means of constraints so that they adapt to the conditions in the environment. Starting from the closure of internal constraints, it also results in the interactive dimension of the agency by extending the causal powers of constraints on the boundary conditions of the whole system (Moreno \& Mossio 2015, p. XXXI). Thus, based on the capacity to act on itself, the capacity of the agent, which becomes thus an autonomous living system, to act on the environment, is created.

From the point of view of dynamical system theory, the constraints existing at the level of any living system are regarded as relations between the variables of the system, which reduce the system's degree of freedom by limiting its trajectory (Hooker 2013, p. 757). Thus, the constraints select the degrees of freedom of the system that can be realised at a certain moment, taking into account the system's parameters. Notwithstanding, the enabling role of the 
constraints is recognised; owing to the complexity of the organism, such role, which determines new coordination of constraints, "provides access to dynamical trajectories inaccessible to the unconstrained system" (Hooker 2013, p. 761). In other words, constraints enable other behaviours when they are joined with other constraints, thus forming a dynamical connection. In this way, in the system's state space, a pattern of action emerges with new degrees of freedom that determine a new evolution of the system.

In terms of organisational view, this ability to manipulate the system's trajectory, owing to the constraints that emerged in the system, is considered a form of adaptive control (Mossio \& Moreno 2010, p. 285). Similarly, also from the perspective of dynamical system theory, the ability of a constraint to alter the path of degrees of freedom of a variable of the system is considered a form of control as well (Pattee 1973, p. 42). These convergent opinions in organisation theory and dynamical system theory come to highlight the idea that the agency does not imply a centred self that should control the system. However, the control of living systems is carried out spontaneously due to the constraints of adaptive dynamics of the system.

An important role in the system's adaptive process is played by the regulation of the organism's internal processes. As we have seen, regulation implies a set of constraints, independent from the constitutive ones, which should operate on operational closure when this is endangered (Moreno \& Mossio 2015, p. $33)$. From this perspective, regulation is considered a second-order control, which harnesses the flows of matter and energy of the system to maintain its organisation (Bich et al. 2015, p. 8). In this approach, regulation involves a circular organisation between constraints that contribute to maintaining the organism's internal organisation, which, in turn, contributes to maintaining these constraints (Bich et al. 2015, p. 9).

This means that the dynamics between the regulatory and constitutive constraints create at the level of system an order pattern, which modulates the entire trajectory of the system. Regulation implies that the dynamics between the order patterns, formed at the level of the entire organism, operates locally by controlling the various variables of the organism (Negru 2016b). In this way, the organism has a flexible behaviour, whereby it offers a response to the perturbations in the environment and new possibilities to act in the world. The regulation of the system parameters with a view to creating a coherent pattern of action, which should determine a response of the organism as a whole to the changes in the environment, lies at the origin of the emergence of a self. In this approach, the self is regarded as the invariant topological pattern that characterises the dynamics of any living system (Thomson 2007, p. 260). It results that the self is the consequence of the dynamics of constitutive and regulating constraints of the system, whereby patterns of action are created, which control the organism's behaviour at a given moment. These patterns of action, resulting from the control of the living system's constitutive processes, have as a consequence the convergence of internal processes dynamics with the external processes dynamics in such a way that organism may achieve its own goals. In this way, the self is formed as a dynamic self that does not imply a central core, but it is formed by that bundle of patterns, whose goal is to maintain the organism's identity and unity despite the perturbations in the environment.

The degree of complexity of this self is given by the level of complexity of the patterns of action formed at the level of the organism. According to their 
complexity, the organism's control mechanisms, which create a hierarchy, generate increasingly chaotic patterns, including more and more variables in the system's state space. The more chaotic the attractors, the more complex the dynamic of the self becomes, increasing the system's autonomy degree.

To conclude, agency implies the control of the processes of organism in order to maintain constant the internal variables and enable the organism to act in the world. The dynamical self results from the organism's control mechanisms, which are regulated to coordinate the organism's internal and external dynamics. Thus the autonomy of a living system is not given merely by maintaining constant its internal organisation but also from the dynamics of the organism's control mechanisms, which represent the basis for acting in the world.

\section{c) Prediction and Anticipatory Behaviour}

One of the most important characteristics of any living system is the ability to anticipate the changes in the environment. Based on this ability, living organisms can survive by avoiding surprising situations, which require unexpected responses. Simultaneously, based on the predictive ability, living organisms can develop patterns of action aimed at achieving their long-term goals. Thus, the ability to predict the modifications of the external variables and prepare some responses, which would maintain the organism's long-term viability, is an important component of a living system understood as an agent.

According to a classical theory, an anticipatory system is "a system containing a predictive model of itself and/or of its environment, which allows it to change state at an instant in accord with the model's predictions pertaining to a later instant" (Rosen 2012, p. 313). According to this theory, a significant requirement of anticipatory systems is that they contain an anticipatory model of positions they may occupy their states and variables in the environment. This does not mean that anticipatory systems are representational systems that act inferentially to adjust the organism's behaviour to the variations in the environment. Such a system would imply an internal representation of the organism's internal and external states so that to any modification of an external state, the organism may respond by a modification of an internal variable. This model cannot be viable as the majority of organisms do not have representational abilities.

Generally speaking, anticipatory systems act directly, by means, at the level of state space, of a vector field, which is activated whenever the organism detects a change internally or in the environment. This means that living organisms have the ability to constitute some behavioural patterns only based on expectancies regarding internal or external changes. And these patterns emerged whenever the system's variables are about to shift their values.

Detecting changes in the world does not require awareness of regularities in the environment but only adjusting the behaviour according to the values of the external parameters by activating some pre-established patterns of action. This means that when external parameters reach certain values, the organism can anticipate the shift of the external state, and then, of its own state, merely based on the data from sensory organs. Similarly, internal changes can be anticipated based on the internal control mechanisms of the living system. In both cases, it acts based on patterns of action built based on prior experiences or by internally simulating a situation. 
To put it differently - the organism does not need to have a high degree of complexity to anticipate internal and external changes. It is just that the organism's anticipations are likely to include as many variables as possible, but this depends on the organism's degree of complexity. This very degree also determines whether the organism's anticipations are made in the short or long term.

Starting from here, in the case of organisms with the brain we can also speak of a higher form of regulation called allostasis (Sterling 2012; Schulkin 2011). According to the supporters of this theory, one of the most important functions of the brain is to monitor as large a number of internal and external parameters of the organism as it is possible in order to anticipate its internal and survival needs (Sterling 2012, p. 7). This means that, in the case of the organisms with a brain, an anticipatory regulation implies the anticipation of changes and gives an appropriate response (Schulkin 2011). From this perspective, anticipating internal and external changes becomes an important requirement of the organisms' adaptation and survival in the environment, which does not imply only maintaining constant its internal variables but also the convergence of the organism's internal dynamics with the external one of the milieu.

This means that anticipation, as a process participating in the regulation of the internal milieu, is part of what the organisational view calls adaptive agency (Moreno \& Mossio 2015). In these terms, one can say that second-order constraints, which regulate the internal constitution of an organism, and which is at the origin of its interactive dimension, can anticipate the organism's states so that some behavioural patterns emerge in agreement with the new parameters. Thus, at the level of the organism, an extended state space emerges, which is not made only of its current states but also of the states potentially occupied by the system as a whole. In this way, the dynamical self, which is the result of the organism's control mechanisms, becomes an extended self, which also includes behavioural patterns resulting from the organism's future states. Hence, we can say that all living systems have an extended self whose level of complexity is given by the organism's anticipatory abilities.

To conclude, what one can infer from the presentation of the agency components is that constitutive coupling enables the agent's ability to form patterns of action depending on the changes in the milieu, the control of internal and external processes guides the actions towards a goal. Anticipation implies the formation of patterns of action, taking into account the future states of the organism.

From the characteristics of agency, it results that in the case of living systems, one can speak of an interactive self, the result of the agents' relations with the world, a dynamical self, owing to the bundle of behavioural patterns, which are the consequence of the system's control mechanisms, and an extended self, which can anticipate the future states to be occupied by the organism. Starting from these characteristics of the self, several types of agency can be distinguished, depending on the living system's degree of complexity, namely, of its mechanisms to adapt and survive. 


\section{Types of Agency in Dynamical Living Systems}

As autonomous dynamical systems, organisms have a self owing to the dynamics of their internal organisation, and they are agents able to initiate actions and to act on the milieu so that they survive considering the external changes. This means that agency is an important component of any living organism, which plays an essential role in adapting to the milieu (Moreno \& Mossio 2015; Barandiaran, Di Paolo \& Rohde 2009). Agency represents thus an important component of any living organism, which as part of the world, wants to be an autonomous living system.

However, not all organisms have the same degree of complexity, which means that we cannot speak of the same type of agency in the case of all living systems. Considering the diversity of the biological world, it is not easy to classify the existing types of agency. Therefore, we classified the agency of living systems into three categories, depending on the general structure of the organisms discussed: (1) minimal agency, corresponding to organisms with simple organisation; (2) sensorimotor agency, of which we speak in the case of organisms with a nervous system; and (3) cognitive agency, which characterises the organisms with higher-order cognitive skills.

These forms of agency are discussed according to the three coordinates of any living agent: the way organism is coupled constitutively to the milieu, the control of internal and external processes, and last but not least, how the changes on the internal and external milieu are anticipated. These aspects are discussed both from the biological perspective and the dynamical systems perspective so that a comprehensive explanation of the agency can be reached.

\section{a) Minimal Agency}

One can speak about minimal agency in the case of simple organisms, which do not imply advanced adaptive structures that would allow them complex responses to the challenges of the milieu. In this case, agency implies regulation of the organism's organisational closure, thus achieving, from a biological point of view, a minimal form of metabolism (Moreno \& Mossio 2015, p. 94). This means that the regulation of minimal agents is only a form of homeostasis, which involves maintaining the organism's internal variables. This is achieved by the control of the organism's internal processes, despite the perturbations in the milieu, so that the organism's identity and unity may be maintained. In other words, minimal agency results from the recursivity of a living system's internal processes, which contributes to the maintenance of its internal organisation.

From an interactive point of view, minimal agency, which is a metabolic agency, implies pursuing some functional actions, such as chemical and energetic exchanges with the exterior, with a view to self-maintaining (Moreno \& Etxeberrria 2005, p. 166). This is possible owing to the physical boundary that separates the organism from the world (i.e., membrane), whereby living organisms create their internal space, enabling the organism's basic form of coupling with the world. This coupling implies only the detection of the changes in the milieu owing to the organism's receptors. To these changes, minimal agents will only respond with basic adaptive reactions (such as gender, adjusting internal processes or releasing chemical substances). In other words, minimal agency characterises organisms with several adaptive functions that integrate into a unitary whole due to their internal organisation. 
Even if they do not imply cognitive skills, organisms with minimal agency can anticipate internal changes, according to the changes detected in the milieu. ${ }^{11}$ Prediction refers, in this case, to the anticipation of internal processes of the organism, based on the information received from external receptors. Thus, the living system can prepare the activation of some internal processes based on predicting the sequence of some events of thermic or chemical changes in the milieu.

From the point of view of dynamical systems, organisms with minimal agency have a limited state space, where only simple behavioural patterns can emerge. These action patterns imply few variables and can instantiate low degrees of freedom. Therefore, such organisms have constitutive or minimal autonomy, which implies only adaptive responses to the changes in the milieu that would ensure the organism's survival and find the necessary resources to maintain its basic functions (Negru 2016b). To put it differently, minimal autonomy consists of adapting the organism's internal dynamics to the dynamic of the milieu so that the organism becomes part of the milieu.

In conclusion, minimal agency is a characteristic of organisms with minimal self, which results from the integration in a whole of the basic adaptive functions of any biological system. Given the basic structures, such an organism has a coupling with the world whereby it can only perceive the external changes and model its internal space in agreement with them. Control, in this case, refers to maintaining constant the internal variables by creating an order parameter with simple degrees of freedom, which are the result of the organism's internal organisation (Negru 2016a). Such simple patterns are also created as a result of the anticipation of the changes in the milieu, implying the modelling of the processes and the organism's internal space. Consequently, minimal agency is a characteristic of organisms with a minimal self and minimal autonomy, which means that their patterns of action aim mainly to maintain their own internal organisation and not their action in the world.

\section{b) Sensorimotor Agency}

In the case of organisms with nervous system, one can speak of a new way of organisation of internal components of living systems, but also of a new way to relate to the milieu. The nervous system is considered as a new subsystem of the organism. It represents a new level, detached from the metabolic one (Moreno \& Etxeberria 2005). ${ }^{12}$ This means that the nervous system processes the energy resulting from the organism's metabolic processes to constitute a dynamic level that would be free from the constraints of the biochemical level (Barandiaran \& Moreno 2008, p. 336). The nervous system provides the organism with new possibilities to respond to the challenges of the milieu, which no longer consist of organic reactions to the changes in the milieu, but they imply acting efficiently on the world to achieve the goals of the living system.

It results from here that the nervous system provides the possibility that the organism perceives the world in terms of the organism's action abilities. Cou-

11

For example, the bacterium that can anticipate internal tendencies (Mossio \& Moreno 2010, p. 285).
12

Although, in order to function, it depends on the organism's metabolic processes. 
pling with the world is achieved by connecting sensory information with the living system's motor abilities, wherefrom sensorimotor loops result. In this way, coupling with the world is no longer achieved by simple responses to the changes in the world, but it implies interactive patterns, whereby the organism gains by its actions information about the milieu, which it transforms in goals for its actions. Thus, coupling with the world determines the emergence of several perception-action patterns, which connect the organism to the environment.

One of the consequences of this new way of coupling with the world is represented by the fact that the organism's actions are oriented towards the external world and guided by external norms. This means that sensorimotor loops are guided by external goals (Di Paolo 2005, p. 439), generating patterns of action that no longer pursue the regulation of their constitutive level. Moreover, another consequence of the sensorimotor coupling with the world is the fact that the organism perceives the world according to its action possibilities, namely, according to affordances (Gibson 1977), which guides its behaviour. In this way, the world is perceived not only through the stimuli influencing the organisms' sensory organs, but, qualitatively (Moreno \& Etxeberria 2005), by means of the importance objects have for the achievement of a living system' goals. It results from here that sensorimotor agency implies understanding the world, not in a representational manner, but in a pre-reflective way, depending on the organism's motor abilities (Thompson 2007, p. 247).

Starting from here, we can say that the nervous system endows the organism with a type of higher control, which no longer implies merely to maintain constant the internal variables of the organism by controlling the metabolic processes and the exchanges with the exterior. Control takes the form of dynamical regulation, whereby various subsystems of the organism - musculoskeletal dynamics, neuroendocrine system etc. (Moreno \& Mossio 2015, p. 176) - are coordinated by an order pattern, guided by the flow of information coming from the exterior. To the extent that the interaction with the milieu is an epistemic one, meaning that it implies gaining some information by the organism, information that would trigger its actions (Etxeberria, Merelo \& Moreno 1994, p. 53), the control provided by the nervous system becomes an epistemic one. This means that we no longer speak of biochemical responses to the variation of the milieu but of the embedding of the organism's internal and external variables in a pattern of action that would increase the chances of the organism to achieve its goals.

An important role in this process is also played by the anticipation of the results of the organism's actions. Sensorimotor loops allow the organism to build internally virtual interactions with the environment, which, assisted by emotions, allow the emergence of complex anticipatory behaviour (Moreno $\&$ Etxeberria 2005, p. 168). In this way, a living system with the nervous system can anticipate not only the internal changes of the system, as a result of external changes, but also the consequences of its actions. Thus, it can select the most appropriate patterns of action to the fulfilment of its actions.

To conclude, the nervous system can be regarded as a dynamical, highly dimensional, and non-linear system, which determines the emergence in the organism of some complex patterns of action that coordinate a wide variety of states of the organism (Moreno \& Mossio 2015, p. 175-176). Owing to the nervous system, the organism's state space is no longer restricted to the states potentially to be occupied, as a result of the organism's metabolic reactions, 
but it forms a dynamical landscape, with multiple attraction pools that correspond to the action possibilities detected in the milieu. Thus, at the level of the organism, multiple attractors with higher complexity and multiple degrees of freedom emerge. It allows the organism to achieve a goal in various ways. Thus, the nervous system enables the organism different ways to act in the world, which would provide extended autonomy, with a multi-dimensional state space and many degrees of freedom.

\section{c) Cognitive Agency}

It is a type of agency that we encounter in the case of organisms with higher-order cognitive skills. We refer here to multicellular organisms, with a complex cognitive life, characterised by higher forms of awareness and self-consciousness. Consciousness represents a new level of the organism that provides a top-down possibility of self-organisation according to some other dynamics, different from the one of the nervous system. This is owing to the fact that the emergence of consciousness, as a result of the coordination between the brain and its different parts, implies the creation of functionally meaningful information (Kelso \& Engstrøm 2008, p. 106). According to this approach, the informational level is considered to be at the origin of conscious agency, which, thus, can influence the behaviour of an organism. This means that the neural network dynamics determine the emergence of a semantic level that controls, in informational terms, the output of the system (Juarrero 2009, p. 90).

It results from here that by constitutive coupling with the world, organisms with consciousness enact the world in a meaningful way. In this way, to the objects in the exterior, new meanings are added that no longer have connections with the organism's motor abilities. Thus, the world is perceived as having more meanings and as being divided into different fields of action. This situation determines the activation of some varied patterns of action, which are conducted according to different norms, depending on the meanings we assign to the objects. Moreover, the informational level that becomes communicable through language offers the possibility to interact directly with other persons and create some joint actions. In addition, the others' narratives can be the basis of recreating some situations we have not experienced (Wilson 2002 , p. 626) and of some offline responses to such challenges. In this way, the informational field opened by consciousness creates a multi-dimensional state space, with multiple possible responses and actions.

The emergence of the informational level allows for a different control of the organism, which implies more than the sensorimotor loop with the exterior. Consciousness organises the life of the living systems, incorporating automated responses in long-term action patterns that take into account the possible changes that occurred in the natural or social milieu. This means that organisms with consciousness can develop complex plans that would take into account many variables in the development of action. The behaviour of such organisms is thus guided not only by short-term intentions, whereby immediate needs are met but also by long-term plans that aim at achieving future goals. In other words, cognitive agency implies "the ability to control goal/ task-related, deliberate thought" (Metzinger 2013), whereby the organism's behaviour is guided on a short and long term.

From the point of view of the dynamical systems theory, the control exerted by consciousness is a consequence of the fact that it is a control parameter 
(Negru 2016b) or order parameter (Freeman 1999, p. 157) able to influence all the variables of the system. This means that the metacognitive level of consciousness can coordinate the dynamics of the other level of the system so that, at its level, multi-dimensional patterns of action may emerge. In other words, consciousness determines the emergence of strange attractors, which are not chaotic, but highly-complex (Juarrero 1999, p. 158), but which provides the organism with many action possibilities as they have many degrees of freedom.

Last but not least, organisms with higher-order cognitive skills rely on their predictive actions and the anticipation of changes in the milieu. In this process, a significant role is assigned to the brain, namely the role to anticipate both the organism's local needs so that resources are distributed adequately between the process of the organism, and to the needs resulted from the organism's coupling with the world (Sterling 2004; Sterling 2012). In this way, the brain builds patterns of action with several degrees of freedom that would respond to the changes potentially to occur in the milieu.

Prediction represents a major component of the organism's adaptive process. This can also be explained, starting from the free-energy principle (Friston 2010). According to Friston's approach, due to coupling with the world, organisms are subjected to some permanent energetic and informational exchanges, which they need to regulated so that to maintain their equilibrium with the exterior. This means that they should minimise their free-energy by predicting, by the brain - which functions as an inference machine that builds a model of the world - sensory inputs (Friston 2010, p. 129). In this way, the brain has an ongoing predictive activity, which contributes to the emergence of an extended state space, which includes not only the present states of the organism but also its states potentially to be occupied depending on the variables in the milieu.

To conclude, organisms with higher-order cognitive skills have a cognitive or conscious self, which implies regulating the organism's behaviour according to some ideas, plans and goals, which the organism consciously sets and determines the awareness of the self as a person (Negru 2016b). In this way, the organism achieves a strong or a personal autonomy (Negru 2016a), which means that it has an extended state space where behavioural patterns with unpredictable trajectories and multi-dimensional degrees of freedom emerge. Agency in any of its forms involves the autonomy of the organism. The possibility to act in the world provides the organisms with the possibility to configure behavioural patterns with increasingly advanced degrees of freedom, depending on the organism's degree of complexity. In this way, the organism gains extended autonomy, responding to environmental challenges and creates adaptative patterns depending on the anticipated external changes.

\section{Conclusion}

From the description of how the self emerges, one can infer that it is not a substantial component of the organism. However, the self is a consequence of the dynamics of behavioural patterns resulting from the organism's control mechanisms that contribute to the organism's adaptation to the milieu. From this perspective, the role of the self is to coordinate these patterns in order to reach the best adaptation of the organism to environmental conditions. 
As a result of the adaptive ability of a living system, the self is at the origin of the agency of organism, more precisely, its ability to act in the world. Therefore, it can be described in terms of three characteristics that differ from the classical conception of the self. Thus, it is an interactive self, which results from the organism's coupling the world, it is a dynamical self, meaning that it is the consequence of the bundle of adaptive patterns of action, and it is an extended self, generated by the ability to predict, necessary to any organism in order to survive. Starting from here, one can also describe three types of agency, which characterise living systems and are at the origin of three types of autonomies: minimal agency, which is characteristic to organisms with minimal autonomy, namely they achieve only the basic adaptive functions, sensorimotor agency, which relies on the existence of the nervous system, which, owing to the coupling of dynamics with the world, provides an extended autonomy, with various degrees of freedom, and cognitive agency, specific to organisms with higher-order cognitive skills, which have the highest degree of autonomy of living systems, having the ability to form patterns of action with unpredictable trajectories and multi-dimensional degrees of freedom.

It results that the self, as a consequence of the patterns of action of a living system, is in close connection with the system's autonomy. Depending on the complexity of the organism's patterns of action, the organism can provide varied responses to the challenges in the milieu. Continually more complex degrees of freedom emerge at the system's level. In this way, the organism gains a certain degree of autonomy, consisting of the totality of the system's degrees of freedom. Thus, the autonomy of a living system is a consequence of the degrees of freedom of the system's adaptive patterns of action, which are at the origin of the emergence of the self. The autonomy of a living system and the self are thus related phenomena, resulting from the degrees of freedom of the patterns of action that emerge in the living system.

\section{Literature}

Barandiaran, Xabier E.; Moreno, Alvaro (2008): "Adaptivity: From metabolism to behaviour", Adaptive Behavior 16 (2008) 5, pp. 325-344, doi: https://doi. org/10.1177/1059712308093868.

Barandiaran, Xabier E.; Di Paolo, Ezequiel; Rohde, Marieke (2009): "Defining Agency: Individuality, Normativity, Asymmetry, and Spatio-temporality in Action", Adaptive Behavior 17 (2009) 5, pp. 367-386, doi: https://doi.org/10.1177/1059712309343819.

Beer, Randall D. (1995): “A dynamical systems perspective on agent-environment interaction", Artificial intelligence 72 (1995) 1-2, pp. 173-215, doi: https://doi. org/10.1016/0004-3702(94)00005-1.

Bich, Leonardo; Moreno, Alvaro (2016): "The role of regulation in the origin and synthetic modelling of minimal cognition", Biosystems 148 (2016), pp. 12-21, doi: https://doi. org/10.1016/j.biosystems.2015.08.002.

Bich, Leonardo et al. (2015): "Biological regulation: controlling the system from within", Biology \& Philosophy 31 (2015) 2, pp. 1-28 [237-265], doi: https://doi.org/10.1007/ s10539-015-9497-8.

Collier, John (2004): "Self-organisation, individuation and identity", Revue internationale de philosophie 59 (2004), pp. 151-172.

Damasio, Antonio (2010): Self Comes to Mind: Constructing the Conscious Brain, Pantheon Books, New York. 
Di Paolo, Ezequiel A. (2005): "Autopoiesis, adaptivity, teleology, agency", Phenomenology and the Cognitive Sciences 4 (2005) 4, pp. 429-452, doi: https://doi.org/10.1007/s11097005-9002-y.

Di Paolo, Ezequiel A.; Iizuka, Hiroyuki (2008): "How (not) to model autonomous behavior", BioSystems 91 (2008) 2, pp. 409-423, doi: https://doi.org/10.1016/j. biosystems.2007.05.016.

Deacon, Terrence W. (2011): Incomplete nature: How mind emerged from matter, W. W. Norton \& Company, New York.

Dennet, Daniel (1992): “The Self as a Center of Narrative Gravity”, in: Frank S. Kessel, Pamela M. Cole, Dale L. Johnson (eds.), Self and Consciousness: Multiple Perspectives, Taylor \& Francis, London - New York, pp. 1-18 [Electronic version].

Descartes, René (1996 [1641]): Meditations on First Philosophy. With selections from the Objections and Replies, trans. John Cottingham, Cambridge University Press, Cambridge.

Etxeberria, Arantza; Merelo, Juan Julian; Moreno, Alvaro (1994): "Studying Organisms with Basic Cognitive Capacities in Artificial Worlds", Intellectica 18 (1994) 1, pp. 45-69, doi: https://doi.org/10.3406/intel.1994.1451.

Freeman, Walter J. (1999): "Consciousness, Intentionality and Causality", Journal of Consciousness Studies 6 (1999) 11-12, pp. 142-172.

Friston, Karl (2010): “The free-energy principle: a unified brain theory?”, Nature Reviews Neuroscience 11 (2010) 2, pp. 127-138, doi: https://doi.org/10.1038/nrn2787.

Froese, Tom; Di Paolo, Ezequiel A. (2011): "The enactive approach: Theoretical sketches from cell to society", Pragmatics \& Cognition 19 (2011) 1, pp. 1-36, doi: https://doi. org/10.1075/pc.19.1.01fro.

Gallagher, Shaun (2005): How the Body Shapes the Mind, Clarendon Press, Oxford.

Gallagher, Shaun (2013): “A Pattern Theory of Self”, Frontiers in Human Neuroscience 7 (2013), article 443, pp. 1-7, doi: https://doi.org/10.3389/fnhum.2013.00443.

Gibson, James J. (1977): “The Theory of Affordances”, in: Robert E. Shaw, John Bransford (eds.), Perceiving, Acting, and Knowing: Towards an Ecological Psychology, Hillsdale (NJ), Lawrence Erlbaum Associates, pp. 67-82.

Hooker, Cliff (2013): "On the Import of Constraints in Complex Dynamical Systems", Foundations of Science 18 (2013) 4, pp. 757-780, doi: https://doi.org/10.1007/s10699012-9304-9.

Hume, David (2009 [1739]): A Treatise of Human Understanding, Oxford University Press, Oxford.

Juarrero, Alicia (1999): Dynamics in Action: Intentional Behavior as a Complex System, MIT, Cambridge (MA).

Juarrero, Alicia (2009): "Top-down Causation and Autonomy in Complex Systems", in: Nancey Murphy, George F. R. Ellis, Timothy O'Connor (eds.), Downward Causation and the Neurobiology of Free Will, Springer, Berlin - Heidelberg, pp. 83-102.

Kant, I. (1965 [1781]): Critique of Pure Reason, trans. Norman Kemp Smith, St. Martin's Press, New York.

Kelso, J. A. Scott; Engstrøm, David A. (2008): The Complementary Nature, MIT, Cambridge (MA) - London.

Locke, J. (1979 [1690]): An essay concerning human understanding, Oxford University Press, Oxford.

Maturana, Humberto R.; Varela, Francisco J. (1980): Autopoiesis and cognition. The realisation of the living, D. Riedel, Dordrecht - Boston - Lancaster.

Maturana, Humberto R.; Varela, Francisco J. (1992): The Tree of Knowledge: The biological roots of human understanding, trans. Robert Paolucci, Shambhala, Boston. 
Metzinger, T. (2013): "The myth of cognitive agency: subpersonal thinking as a cyclically recurring loss of mental autonomy", Frontiers in psychology 4 (2013), article no. 931, pp. 1-19, doi: https://doi.org/10.3389/fpsyg.2013.00931.

Moreno, Alvaro; Etxeberria, Arantza (2005): "Agency in Natural and Artificial Systems", Artificial Life 11 (2005) 1-2, pp. 161-175, doi: https://doi.org/10.1162/1064546053278919.

Moreno, Alvaro; Mossio, Matteo (2015): Biological Autonomy: A Philosophical and Theoretical Enquiry, Springer.

Mossio, Matteo; Bich, Leonardo (2014): "What makes biological organisation teleological?", Synthese 194 (2014) 4, pp. 1089-1114, doi: https://doi.org/10.1007/s11229$\underline{014-0594-z}$.

Mossio, Matteo; Moreno, Alvaro (2010): “Organisational closure in biological organisms", History and Philosophy of the Life Sciences 32 (2010) 2-3, pp. 269-288.

Negru, Theodor (2016a): "Self-organisation and autonomy: Emergence of degrees of freedom in dynamical systems", Filosofia Unisinos 17 (2016) 2, pp. 121-131, doi: https:// doi.org/10.4013/fsu.2016.172.05.

Negru, Theodor (2016b): "Autonomy and control. Dynamics of degrees of freedom in living systems", Filozofia Nauki 24 (2016) 4, pp. 5-25.

Neisser, Ulric (1998): “Five kinds of self-knowledge", Philosophical Psychology 1 (1998) 1, pp. 35-59, doi: https://doi.org/10.1080/09515088808572924.

Pattee, Howard Hunt (1973): "Physical problems of the origin of natural controls", in: Alfred Locker (ed.), Biogenesis Evolution Homeostasis, Springer, Berlin - Heidelberg, pp. 41-49.

Rochat, Philippe (1995): "Early Objectification of the Self", in: Philippe Rochat (ed.), The Self in Infancy: Theory and Research, Elsevier Science, Amsterdam, pp. 53-72.

Rosen, Robert (2012): “Anticipatory systems”, in: Anticipatory Systems. Philosophical, Mathematical, and Methodological Foundations, Springer, New York, pp. 313-370.

Rudrauf, David; Damasio, Antonio (2006): “The biological basis of subjectivity: a hypothesis", in: Uriah Kriegel, Kenneth Williford (ed.), Self-Representational Approaches to Consciousness, Bradford Book - MIT Press, Cambridge (MA), pp. 423-465.

Ruiz-Mirazo, Kepa; Moreno, Alvaro (2004): "Basic Autonomy as a Fundamental Step in the Synthesis of Life", Artificial Life 10 (2004) 3, pp. 235-259, doi: https://doi. org/10.1162/1064546041255584.

Ruiz-Mirazo, Kepa; Moreno, Alvaro (2012): “Autonomy in evolution: from minimal to complex life", Synthese 185 (2012) 1, pp. 21-52, doi: https://doi.org/10.1007/s11229-0119874-Z.

Schulkin, Jay (2011): "Social Allostasis: Anticipatory Regulation of the Internal Milieu", Frontiers in Evolutionary Neuroscience 2 (2011), article no. 111, pp. 1-15, doi: https://doi. org/10.3389/fnevo.2010.00111.

Sterling, Peter (2004): "Principles of Allostasis: Optimal Design, Predictive Regulation, Pathophysiology, and Rational Therapeutics", in: Jay Schulkin (ed.), Allostasis, Homeostasis, and the Costs of Physiological Adaptation, Cambridge University Press, Cambridge, pp. 17-64, doi: https://doi.org/10.1017/CBO9781316257081.004.

Sterling, Peter (2012): "Allostasis: a model of predictive regulation", Physiology \& Behavior 106 (2012) 1, pp. 5-15, doi: https://doi.org/10.1016/j.physbeh.2011.06.004.

Strawson, Galen (1999): “The self and the SESMET”, Journal of Consciousness Studies 6 (1999) 4, pp. 99-135.

Thagard, Paul (2014): "The self as a system of multi-level interacting mechanisms", Philosophical Psychology 27 (2014) 2, pp. 145-163, doi: https://doi.org/10.1080/09515 089.2012.725715.

Thompson, Evan (2007): Mind in Life: Biology, Phenomenology, and the Sciences of Mind, Harvard University Press, Cambridge (MA). 
Varela, Francisco J. (1992): "Autopoiesis and a biology of intentionality", in: Barry McMullin (ed.), Autopoiesis and Perception, Dublin City University, Dublin, pp. 4-14.

Varela, Franscisco J. (1997): "Patterns of Life: Intertwining Identity and Cognition”, Brain and Cognition 34 (1997) 1, pp. 72-87, doi: https://doi.org/10.1006/brcg.1997.0907.

Wilson, Margaret (2002): "Six Views of Embodied Cognition", Psychonomic Bulletin \& Review 9 (2002) 4, pp. 625-636, doi: https://doi.org/10.3758/bf03196322.

Zahavi, Dan (2003): "Phenomenology of Self", in: Tilo Kircher, Anthony David (eds.), The Self in Neuroscience and Psychiatry, Cambridge University Press, Cambridge, pp. 56-75.

Zahavi, Dan (2005): Subjectivity and Selfhood: Investigating the First-Person Perspective, MIT Press, Cambridge (MA).

Zahavi, Dan (2007): "Self and Other: The Limits of Narrative Understanding", Royal Institute of Philosophy Supplements 60 (2007), pp. 179-202.

\title{
Teodor Negru
}

\section{Sebstvo, svjesno djelovanje i autonomija u dinamičkim živućim sustavima}

\begin{abstract}
Sažetak
U ovom je radu moja namjera ponuditi novo objašnjenje sebstva iz teorijskih perspektiva biologije i dinamičkih sustava. To znači da podržavam ideju da je sebstvo posljedica bioloških kontrolnih mehanizama, bilo unutarnjih procesa ili kao ishod međudjelovanja organizma $i$ okoliša. Iz perspektive teorije dinamičkih sistema, sebstvo se može razumjeti kao svežanj uzoraka proizlazećih iz prilagodbe živućeg sustava na uvjete okoliša. U prvom dijelu rada, sebstvo se razumijeva polazeći od tri obilježja živućih sustava koji su rezultat samoorganizacije organske materije: identitet, jedinstvo i samoodržavanje. U drugom dijelu, raspravljam o jednom od najvažnijih obilježja sebstva: svjesnom djelovanju. Značenju svjesnog djelovanja pristupa se kao da se sastoji od tri dijela: sprega organizma sa svijetom, upravljanje unutarnjim $i$ vanjskim procesima te predviđanje. Zaključno, raspravljam o problemu veze između sebstva i autonomije, pri čemu razmatram sebstvo kao posljedicu stupnjeva slobode živućeg sustava.
\end{abstract}

Ključne riječi

sebstvo, svjesno djelovanje, autonomija, dinamički sustavi, autopoieza

\section{Teodor Negru}

\section{Selbst, Handlungsfähigkeit und Autonomie in dynamischen lebenden Systemen}

\begin{abstract}
Zusammenfassung
Mit diesem Artikel beabsichtige ich, eine neuartige Erklärung des Selbst aus theoretischen Perspektiven der Biologie und dynamischen Systeme vorzulegen. Dies bedeutet, dass ich die Idee bekräftige, das Selbst sei die Konsequenz biologischer Kontrollmechanismen, seien es interne Prozesse oder als Ausgang der Interaktion von Organismus und Umwelt. Aus der Perspektive der Theorie dynamischer Systeme kann das Selbst als ein Bündel von Mustern aufgefasst werden, welche der Anpassung eines lebenden Systems an die Umweltbedingungen entsprießen. Im ersten Teil der Arbeit wird das Selbst ausgehend von drei Merkmalen lebender Systeme erfasst, die das Ergebnis der Selbstorganisation organischer Materie sind: Identität, Einheit und Selbsterhaltung. Im zweiten Teil bespreche ich eine der bedeutsamsten Eigenschaften des Selbst: Handlungsfähigkeit. Die Bedeutung der Handlungsfähigkeit wird in der Art angegangen, als bestünde sie aus drei Teilen: der Kopplung des Organismus an die Welt, der Leitung interner und externer Prozesse und der Antizipation. Abschließend diskutiere ich
\end{abstract}


das Problem der Verknüpfung zwischen Selbst und Autonomie, wobei ich das Selbst als Ausfluss der Freiheitsstufen eines lebenden Systems erachte.

\section{Schlüsselwörter}

Selbst, Handlungsfähigkeit, Autonomie, dynamische Systeme, Autopoiese

\section{Teodor Negru}

\section{Le soi, l'action consciente et}

\section{l'autonomie dans les systèmes dynamiques vivants}

\section{Résumé}

Dans ce travail, mon intention est de proposer une nouvelle explication du soi issue des théories en biologie et des systèmes dynamiques. Cela signifie que je soutiens l'idée selon laquelle le soi est la conséquence des mécanismes de contrôles biologiques, autant des processus internes, qu'en tant que résultat de l'interaction entre l'organisme et l'environnement. Selon la perspective de la théorie des systèmes dynamiques, le soi peut être compris comme un faisceau de causes qui découlent de l'adaptation des systèmes vivants aux conditions de l'environnement. Dans la première partie de ce travail, le soi est considéré sur la base de trois caractéristiques des systèmes vivants qui sont le résultat de l'auto-organisation de la matière vivante : l'identité, l'unité et l'auto-conservation. Dans la deuxième partie, je discute de l'une des plus importantes caractéristiques du soi : l'action consciente. La signification de l'approche de l'action consciente est composée de trois parties: la relation de l'organisme avec le monde, l'organisation des processus internes et externes et la prévision. En conclusion, je discute du problème de la relation entre le soi et l'autonomie, en considérant le soi comme une conséquence du degré de liberté du système vivant.

\section{Mots-clés}

soi, action consciente, autonomie, système dynamique, autopoïèse 